PRELIMINARY COMMUNICATION

\section{Use of Glucagon in the Treatment of Acute Diverticultis*}

\author{
O. DANIEL, P. K. BASU, H. M. AL-SAMARRAE
}

British Medical fournal, 1974, 3, 720-722

\section{Summary}

Glucagon given intravenously to 20 patients with acute diverticulitis was followed by symptomatic relief within an average of 12 hours and obviated the need for therapy with analgesics or other antispasmodics. In a similar group of patients receiving conventional treatment symptoms persisted for an average of 96 hours. The administration of glucagon had no apparent effect on abdominal symptoms which mimicked those of diverticulitis but were caused by other conditions. There was no clinically apparent difference in effectiveness between continuous infusion and intermittent injection of glucagon.

\section{Introduction}

Attacks of acute diverticulitis are characterized by abdominal pain with localized tender swelling of the iliac or pelvic colon. Bowel function is usually disturbed, causing either obstinate constipation, diarrhoea, or, rarely, alternating constipation and diarrhoea. In addition there may be pyrexia with leucocytosis, nausea, vomiting, abdominal distension, and occasionally passage of mucus or blood per rectum. Though clinical diagnosis is usually easy the presence of other conditions must always be suspected until excluded by subsequent investigation, particularly when obstructive features or swelling are considerable. The disease is temporarily incapacitating and if at all severe, justifies admission to hospital. Conventional treatment includes the administration of analgesics, intestinal antispasmodics, and, if there are signs of inflammation, broad-spectrum antibiotics. Nasogastric suction and intravenous fluids may be required if there is evidence of obstruction or dehydration. Response to such treatment is generally satisfactory though slow, and for the few days before improvement is manifest the condition may cause anxiety.

A suggestion that glucagon may be beneficial in acute pancreatitis (Knight et al., 1971) stimulated our interest in this hormone and led to the perusal of reports that, among many other actions, glucagon reduced intestinal motility (Dotevall and Kock, 1963; Necheles et al., 1966). It has been suggested that symptoms of diverticular disease are related to colonic muscular hypertrophy (Morson, 1963) and hypermotility (Painter, 1962). In view of the inhibitory effect of glucagon on bowel motility and its relative freedom from adverse reactions, except for

*Based on a paper read at the 2nd Joint Meeting of the European Society for Experimental Surgery with the Surgical Research Society and the Society of University Surgeons, Garmisch-Partenkirchen/F.R.G. September 1973.

Royal Alezandra Hospital, Rhyl

O. DANIEL, M.S., F.R.C.S., Consultant Surgeon

P. K. BASU, M.D., F.R.C.S., Surgical Registrar

H. M. AL-SAMARRAE, P.R.C.s., Surgical Research Registrar. (Present address: Department of Surgery, University of Baghdad, Iraq) occasional nausea and vomiting (Lefebvre and Unger, 1972), we decided to carry out a therapeutic trial of this hormone in patients requiring hospital treatment for acute diverticulitis. The results of glucagon therapy were compared with those of conventional treatment in a matched group of patients admitted during the 18-month period preceding the glucagon trial.

We also studied the effect of glucagon on colonic motility when given in single bolus injections as compared with continuous infusion.

\section{Patients and Methods}

Twenty consecutive patients with symptoms of acute diverticulitis admitted as emergencies to one surgical unit during the two-year period ending December 1973 received intravenous injections of glucagon as primary treatment. Patients requiring immediate surgery were excluded from this series as were those in whom subsequent investigation showed that the presenting symptoms could have been attributed to other conditions. Fourteen of the patients were women and six were men, their ages ranging from 31 to 88 years (mean 69 years). Acute symptoms had been present for periods ranging from one to 40 days (mean 10 days) before glucagon therapy was started. Eleven patients had had previous similar attacks, and the remainder gave no history of earlier symptoms of diverticular disease.

All patients complained of abdominal pain. In 13 a tender mass was palpable in the left iliac fossa or pelvis and in the remainder there was tenderness with guarding or rigidity on the left side of the abdomen. Nine patients complained of constipation and nine of the passage of frequent small solid or loose motions, in four accompanied by mucus and in one by both mucus and blood. Ten patients had had vomiting, five nausea, and six abdominal distension. The oral temperature was $38^{\circ} \mathrm{C}$ or over in five patients and in three the leucocyte count exceeded $15,000 / \mathrm{mm}^{3}$. All of these patients were diagnosed on admission as suffering primarily from acute diverticulitis (see table). In addition four were suspected of concomitant pericolic abscess, two of subacute intestinal obstruction, and two of associated carcinoma coli, but in all cases the results of clinical sigmoidoscopy and contrast radiography together with the patients' subsequent clinical progress ruled out the suspicion of an associated condition.

\section{GLUCAGON TREATMENT}

Crystalline glucagon (Lilly) was dissolved immediately before use in the accompanying diluting solution. In the first eight patients $10 \mathrm{ml}$ of the solution containing $1 \mathrm{mg}$ of glucagon was injected directly into a forearm vein within 5-8 seconds. In the next six patients the solution was further diluted with sodium chloride injection so that $1 \mathrm{mg}$ was contained in $20 \mathrm{ml}$ of solution, which was administered slowly into a vein over 8-10 minutes. Each patient received an injection at four-hour intervals over 36 hours - a total of nine doses. The remaining six patients received $4.5 \mathrm{mg}$ of glucagon in $50 \mathrm{ml}$ of diluent by continuous intravenous infusion via a Sage pump over two consecutive periods of 18 hours. Inititally the diet was restricted to fluids, gradually reverting to normal as symptoms subsided. Daily supplements of $50 \mathrm{~g}$ of unrefined bran were given. All patients were strongly advised to continue taking the bran regularly thereafter. Two of the four patients with signs suggestive of actual or impending pericolic abscess were given courses of ampicillin and the other two courses of tetracycline.

In 11 patients glucagon therapy was started within an hour or two of admission to hospital but in the remaining nine there was 
Clinical Details of 35 Patients with Acute Diverticulitis, 20 treated with Glucagon and 15 treated Conventionally

\begin{tabular}{|c|c|c|c|c|c|c|c|c|c|c|c|}
\hline \multirow{2}{*}{ Case No. } & \multirow{2}{*}{ Age and Sex } & \multirow{2}{*}{ Pain } & \multirow{2}{*}{$\begin{array}{c}\text { Consti- } \\
\text { pation }\end{array}$} & \multirow{2}{*}{ Diarrhoea } & \multirow{2}{*}{ Vomiting } & \multirow{2}{*}{ Nausea } & \multicolumn{2}{|c|}{ Rectal Discharge } & \multirow{2}{*}{$\begin{array}{c}\text { Abdominal } \\
\text { Signs }\end{array}$} & \multirow{2}{*}{$\underset{\mathbf{C}^{\circ}}{\text { Temperature }}$} & \multirow{2}{*}{ W.B.C. $/ \mathrm{mm}^{2}$} \\
\hline & & & & & & & Mucus & Blood & & & \\
\hline \multicolumn{12}{|c|}{ Glucagon-treated Patients } \\
\hline $\begin{array}{r}1 \\
2 \\
3 \\
4 \\
5 \\
6 \\
7 \\
8 \\
9 \\
10 \\
11 \\
12 \\
13 \\
14 \\
15 \\
16 \\
17 \\
18 \\
19 \\
20\end{array}$ & 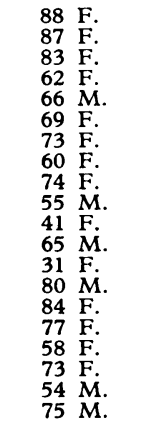 & $\begin{array}{l}+ \\
+ \\
+ \\
+ \\
+ \\
+ \\
+ \\
+ \\
+ \\
+ \\
+ \\
+ \\
+ \\
+ \\
+ \\
+ \\
+ \\
+ \\
+ \\
+\end{array}$ & $\begin{array}{l}+ \text { A. } \\
+ \\
+ \\
+ \\
+ \\
+\end{array}$ & $\begin{array}{l}+ \\
+ \\
+ \\
+ \\
+ \\
+\end{array}$ & $\begin{array}{l}+ \\
+ \\
+ \\
+\end{array}$ & $\begin{array}{l}+ \\
+ \\
+ \\
+ \\
+ \\
+\end{array}$ & $\begin{array}{l}+ \\
+ \\
+\end{array}$ & + & $\begin{array}{l}\text { T.M. } \\
\text { T.M. } \\
\text { T.M. } \\
\text { T.M. } \\
\text { G. } \\
\text { T.M. } \\
\text { G. } \\
\text { T.M. } \\
\text { T.M. } \\
\text { T.M. } \\
\text { T.M. } \\
\text { T.M. } \\
\text { T.M., D. } \\
\text { G., D. } \\
\text { G. } \\
\text { G. } \\
\text { G. } \\
\text { T.M., D. } \\
\text { T.M., D. } \\
\text { G., D. }\end{array}$ & $\begin{array}{l}37 \cdot 5 \\
37 \cdot 0 \\
37 \cdot 1 \\
37 \cdot 2 \\
37 \cdot 0 \\
37 \cdot 0 \\
37 \cdot 5 \\
37 \cdot 0 \\
38 \cdot 0 \\
38 \cdot 2 \\
38 \cdot 0 \\
37 \cdot 0 \\
37 \cdot 5 \\
37 \cdot 0 \\
37 \cdot 5 \\
37 \cdot 0 \\
36 \cdot 5 \\
37 \cdot 2 \\
38 \cdot 0 \\
38 \cdot 3\end{array}$ & $\begin{array}{r}11,600 \\
7,200 \\
7,400 \\
10,300 \\
6,800 \\
9,500 \\
9,100 \\
12,500 \\
10,700 \\
5,600 \\
5,700 \\
8,000 \\
6,500 \\
8,200 \\
9,500 \\
20,200 \\
15,100 \\
24,000 \\
14,000 \\
20,500\end{array}$ \\
\hline \multicolumn{12}{|c|}{ Control Group } \\
\hline $\begin{array}{l}21 \\
22 \\
23 \\
24 \\
25 \\
26 \\
27 \\
28 \\
29 \\
30 \\
31 \\
32 \\
33 \\
34 \\
35\end{array}$ & $\begin{array}{ll}79 & \mathrm{~F} . \\
75 & \mathrm{~F} . \\
84 & \mathrm{M} . \\
76 & \mathrm{~F} . \\
62 & \mathrm{~F} . \\
65 & \mathrm{~F} . \\
64 & \mathrm{~F} . \\
67 & \mathrm{~F} . \\
83 & \mathrm{~F} . \\
70 & \mathrm{M} . \\
70 & \mathrm{~F} . \\
54 & \mathrm{M} . \\
42 & \mathrm{M} . \\
65 & \mathrm{~F} . \\
68 & \mathrm{~F} .\end{array}$ & $\begin{array}{l}+ \\
+ \\
+ \\
+ \\
+ \\
+ \\
+ \\
+ \\
+ \\
+ \\
+ \\
+ \\
+ \\
+\end{array}$ & $\begin{array}{l}+ \\
+ \\
+ \\
+ \text { A. } \\
+ \\
+ \\
+ \\
+ \\
+ \\
+\end{array}$ & $\begin{array}{l}+ \\
+ \text { A. }\end{array}$ & $\begin{array}{l}+ \\
+ \\
+ \\
+ \\
+ \\
+\end{array}$ & $\begin{array}{l}+ \\
+ \\
+ \\
+ \\
+\end{array}$ & $\begin{array}{l}+ \\
+\end{array}$ & + & $\begin{array}{l}\text { G., D. } \\
\text { G. } \\
\text { T.M., D. } \\
\text { T.M. } \\
\text { T.M. } \\
\text { G. } \\
\text { T.M., D. } \\
\text { G. } \\
\text { T.M., D. } \\
\text { T.M. } \\
\text { T.M. } \\
\text { T.M. } \\
\text { G..D. } \\
\text { T.M. } \\
\text { T.M. }\end{array}$ & $\begin{array}{l}36 \cdot 5 \\
37 \cdot 0 \\
37 \cdot 1 \\
37 \cdot 0 \\
37 \cdot 2 \\
37 \cdot 0 \\
37 \cdot 1 \\
37 \cdot 3 \\
37 \cdot 0 \\
37 \cdot 0 \\
36 \cdot 5 \\
38 \cdot 5 \\
38 \cdot 6 \\
37 \cdot 5 \\
38 \cdot 2\end{array}$ & $\begin{array}{r}6,300 \\
6,200 \\
5,100 \\
13,000 \\
4,800 \\
12,500 \\
7,300 \\
7,900 \\
7,400 \\
7,200 \\
13,500 \\
16,600 \\
15,700 \\
15,200 \\
21,000\end{array}$ \\
\hline
\end{tabular}

+ A. = Alternating constipation and diarrhoea.

T.M. = Tender mass in left iliac fosso or pelvis.

D. = Abdominal distension.

a delay of 24-72 hours (mean 48 hours) because of initial doubts about the diagnosis or whether the illness was severe enough to warrant the administration of glucagon. During this preliminary period patients received conventional treatment.

\section{CONVENTIONAL TREATMENT}

Fifteen patients admitted to hospital in the 18-month period immediately preceding the glucagon study were chosen retrospectively to match as closely as possible in age and severity of symptoms those who received glucagon (see table). Twelve of these were women and three were men, ranging in age from $\mathbf{4 2}$ to 84 years (mean 69). Acute symptoms had been present for 1-28 days (mean six days) before the start of conventional treatment. Seven of these patients gave a history of previous similar attacks, and the remainder had had no previous symptoms of diverticular disease. All patients were suffering from abdominal pain and 10 had a tender mass at the site of the left iliac or pelvic colon. The other five had tenderness with guarding or rigidity on the left side of the abdomen. Ten complained of constipation, six of the passage of frequent small solid or loose motions, and one of profuse rectal bleeding. Eight patients experienced vomiting, six nausea, and five abdominal distension. The oral temperature was over $38^{\circ} \mathrm{C}$ in three patients, and in four the leucocyte count exceeded $15,000 / \mathrm{mm} .^{3}$ All patients were diagnosed on admission as suffering primarily from acute diverticultis but three were suspected of having pericolic abscess, two subacute intestinal obstruction, and one associated caroinoma coli as well. These secondary diagnoses were ruled out by subsequent investigation.

The conventional treatment for these patients comprised paracetamol or pethidine in doses adequate to relieve pain, parenteral tetracycline or ampicillin if there was fever or other sign of inflammation, and nasogastric suction and intravenous fluids if there were signs of obstruction or dehydration. Most patients also received repeated intramuscular injections of $20 \mathrm{mg}$ of hyoscine butylbromide or $30 \mathrm{mg}$ of propantheline bromide with the object of relieving colonic muscle spasm. Initially oral feeding was restricted to fluids, but a light diet was given as soon as it could be tolerated, supplemented later with $50 \mathrm{~g}$ of unrefined bran daily. On leaving hospital all patients were strongly advised to persevere with this high residue diet.

\section{Results}

\section{GLUCAGON TREATMENT}

The administration of glucagon was followed within 6-24 hours (mean 12 hours) by virtually complete relief from the main symptoms and also by substantial improvement in general condition. The most constant and noticeable benefit was relief of the pain which was the predominant complaint on admission. No patient receiving glucagon needed analgesics, though these drugs are a necessary part of conventional therapy. The dull aching discomfort related to the tender swelling of the affected segment of bowel disappeared as quickly as did the generalized abdominal pain. Disturbance of bowel function was also corrected within an average of 12 hours. Patients who had suffered constipation, which was often completely resistant to all other treatment including suppositories and enemas, were greatly relieved by the effortless and entirely satsifactory passage of large stools within hours of the administration of glucagon. Patients who had suffered frequent loose bowel movements, in some cases as often as 12 times a day and accompanied by the passage of mucus or blood, were equally relieved when normal bowel function was restored within an average period of 12 hours. Abdominal distension disappeared at the same time as normal bowel action was restored. Palpable masses in the iliac or pelvic colon disappeared more gradually, in periods ranging from 12 hours to 14 days (mean two days). The larger the mass and the longer it had been present before treatment started the longer the interval before it disappeared.

The only unfavourable reaction attributable to glucagon was nausea and vomiting, which occurred in four of the eight patients who received fairly rapid intravenous injection of $1 \mathrm{mg}$ 
of glucagon in $10 \mathrm{ml}$ of diluent. In one patient rapid injection was followed by a severe syncopal attack with nausea and vomiting, but no ill effects followed the slow administration of glucagon to this or any other patient. There was no clinically detectable difference between the results of intermittent injection at four-hourly intervals and continuous infusion. Infusion, however, was less disturbing to the patient and easier for the nursing staff. Patients who continued to take bran, as advised, had no recurrence of symptoms of diverticular disease.

\section{CONVENTIONAL TREATMENT}

Response to conventional treatment though ultimately satisfactory is slow. The early days, during which response to treatment is barely perceptible, are trying to the patients and a cause of anxiety to their attendants. The principal symptomsnamely, pain, disturbance of bowel function, and abdominal distension-persisted in the patients selected for comparison for periods of 1.5-6 days (mean four days) after beginning hospital treatment, during which analgesics and sedatives were required. The characteristic tender colonic mass gradually diminished over an average period of five days.

\section{Discussion}

The relief afforded by glucagon to 20 consecutive patients suffering from severe symptoms of acute diverticulitis encourages us in our belief that a new therapeutic role for this hormone may have been discovered. This belief is strengthened by the fact that glucagon acted so quickly on symptoms which had often persisted over long periods and resisted other treatment. The rapid resolution of abdominal guarding or rigidity, pyrexia, and leucocytosis-even when these were severe enough to raise the suspicion of pericolic abscess-tends to underline the importance of colospasm in the aetiology of acute diverticulitis, a theory propounded on histological grounds by Morson (1963). During the study glucagon was given to every patient in whom the diagnosis of acute diverticulitis, or colospasm, seemed to be a reasonable possibility. As other conditions may cause similar symptoms or occur in conjunction with diverticulitis, not surprisingly in four patients the original clinical impression proved erroneous. The fact that lasting beneficial effects occurred only in patients suffering from uncomplicated acute diverticulitis suggests that glucagon may have a specific action in this condition by its inhibitory action on intestinal motility. If this suggestion is confirmed the hormone may prove to be of diagnostic as well as therapeutic value.

Comparison with a group of patients treated conventionally but selected retrospectively may be open to criticism. We therefore plan to conduct a double-blind comparative study between glucagon and a placebo, which we consider justified on the basis of our data.

We thank the research committee of the Welsh Hospital Board for generous support and Dr. G. L. Smith, of Eli Lilly and Company Limited, Basingstoke, Hants for valuable advice and help. Mr. Rushton of the Dylade Company Ltd., Runcorn, Cheshire kindly loaned a Sage pump, model 240, for the investigation. We thank Mr. R. J. Marshall, director of the department of medical illustration, United Cardiff Hospitals, for the illustrations; Mr. Philip Wade, librarian of the Royal Society of Medicine for valuable help with the references, and Miss Iona Williams for secretarial help.

\section{References}

Dotevall, G., and Kock, N. G. (1963). Gastroenterology, 45, 364

Knight, M. J., Condon, J. R., and Smith, R. (1971). British Medical fournal, 2,440

Lefebvre, P. J., and Unger, R. H. (1972). Glucagon. Oxford, Pergamon Press. Morson, B. D. (1963). British Fournal of Radiology, 36, 385.

Necheles, H., Sporn, J., and Walker, L. (1966). American Fournal of Gastroenterology, 45, 34.

Painter, N. S. (1962). M.S. Thesis, London University.

\section{MEDICAL MEMORANDA}

\section{Case of Post-primary Tuberculosis and Massive Haematemesis}

\author{
B. W. HANCOCK, D. B. BARNETT
}

British Medical fournal, 1974, 3, 722-723

Tuberculous aortitis is extremely rare and the prognosis is grave, most cases progressing to aneurysm formation and rupture (Volini et al., 1962). The case reported her is unique in that the patient had post-primary cryptic disseminated tuberculosis (Proudfoot et al., 1969) presenting with massive haematemesis from a tuberculous aorto-oesophageal fistula without aneurysm formation.

\section{Case History}

The patient, a man aged 52, was admitted to this hospital as an emergency case. He had vomited fresh blood of unknown quantity

\footnotetext{
Section of Therapeutics, Academic Division of Medicine, Royal Infirmary, Sheffield S6 3DA

B. W. HANCOCK, M.B., M.R.C.P., Registrar

D. B. BARNETT, M.B., M.R.C.P., Lecturer
}

passed 2 pints $(1,140 \mathrm{ml})$ of fresh melaena. As he was confused a history was obtained from the relatives. He had been unwell for 12 weeks with anorexia, weight loss, and upper abdominal pain. Other than a daily intake of 6 pints $(3.41$.$) of beer there was nothing$ else relevant in the history.

On admission he was found to be shocked and there was the appearance of recent weight loss. The abdomen was soft with some tenderness in the epigastrium. No masses were palpable and rectal examination showed fresh melaena. The preliminary differential diagnosis included bleeding from peptic ulcer, gastric neoplasm, and oesophageal varices. Haemoglobin was $73 \%$ and he was transfused with 4 units of blood. Next morning he remained confused though the bleeding had stopped. Endoscopy showed some changed blood adherent to the muoosa near the cardia of the stomach. The oesophagus, stomach, and proximal duodenum appeared normal.

The following investigations gave normal results: blood sugar, bleeding and clotting values, serum vitamin $\mathbf{B}_{12}$ and folic acid, serum proteins and electrophoresis, and barium swallow, meal, and follow-through examination. A portable chest $x$-ray film on admission showed miliary nodularity thought to be industrial in origin. This was not seen in later films. Liver function tests showed slightly raised transaminases and the platelet count was 70,000/ $\mathrm{mm}^{3}$. In view of the patient's continued confusion, previous alcohol intake, and abnormal liver function liver disease was considered despite the absence of demonstrable varices. He improved over the next few days though the fever remained. The platelet count returned to normal and it was intended to perform liver biopsy, but the patient collapsed again 12 days after admission with further haematemesis and melaena. He was rapidly transfused with 2 units of plasma and 4 units of blood. His condition worsened and one 